International Business Management 6(2): 213-222, 2012

ISSN: $1993-5250$

(C) Medwell Journals, 2012

\title{
Perception on the Performance Appraisal System Among Malaysian Diplomatic Officers
}

\author{
${ }^{1}$ Haslinda Abdullah and ${ }^{2}$ Karen George Abraham \\ ${ }^{1}$ Faculty of Defence Studies and Management, National Defence University of Malaysia, \\ Kem Sungai Besi, 57000 Kuala Lumpur, Malaysia \\ ${ }^{2}$ Graduate School of Management, Universiti Putra Malaysia, 43400 Selangor, Malaysia
}

\begin{abstract}
The effectiveness of performance appraisal has been a debatable issue for decades as it affects various factors in an employee's career such as rewards, training and more importantly, promotions. This study therefore discusses the perception of the Malaysian Administrative and Diplomatic Service officers on the current performance appraisal system, focusing at appraisal understanding and satisfaction as well as rater's characteristics and dissatisfaction by diplomatic officers. This study employed a survey convenience sampling 106 respondents or $28.7 \%$ of the population sampling responded out of the 370 questionnaires sent out to the government offices. Descriptive analysis was used to describe the findings of the survey. The research finding revealed that a majority of the diplomatic officers agreed that the purpose of appraisal is generally for promotions and agreed that their superiors should be the ones to grade them although grading by peers was agreed by half of the respondents. Although, understanding the appraisal was not an issue, the satisfaction of the current appraisal system was low generally. Where rating method is concerned, most of the officers agreed that rating based on attributing good or poor performance is based on specific behaviors of ratee. However, a high percentage of the officers agreed that favoritism tops the list in areas where biasness may occur and subjectivity of the current system is an issue to address. From the open ended questions, the finding also indicated that there are dissatisfactions regarding the current system and recommendations have been suggested by the officers to overcome these problems. This study is relevant to ascertain the perception of the diplomatic officers on the current performance appraisal system and thus help the management to realize the dissatisfaction of the system. Although there were some limitations, it did not affect the validity of the data. Thus, the information obtained is vital for the policy makers to improve the current system.
\end{abstract}

Key words: Performance appraisals, raters, diplomatic officers, policy makers, employees, Malaysia

\section{INTRODUCTION}

The public sector is the largest employer with almost 1.3 million employees. In any organization, performance appraisal is seen as a critical human resource management function (Roberts, 2003). In the Malaysian public service, performance appraisal is a continuous process of evaluating employee's performance throughout the year. In any performance appraisal carried out, there are always dissatisfaction and problems faced by the ratees. It can be said that the problem is not due to the concept of performance appraisal but the implementation and its design (Dev Kumar, 2005). Roberts (2003) claims that employees performance appraisal assumes a false degree of measurement accuracy, engenders dysfunctional employee conflict and competition and assigns an inordinate amount of responsibility for performance to the employees. It undervalues the importance of the work group and is often used as a control device. Kerssens-van Drongelen and Fisscher (2003) agreed that unethical behavior may have contributed to the lower than expected effectiveness of the performance measurement procedures.

The Public Service Department (PSD) of the Government of Malaysia implemented the New Performance Appraisal System (Sistem Saraan Baru, SSB) in January, 1992 as a strategic step to increase the ability of the public service sector. As time passed and change occurred, there was a need to review this system in line with the current policies of the public sector. In 2002, a new system was introduced to replace the SSB, called the Malaysian Performance Appraisal System (Sistem Saraan Malaysia, SSM) as a tool in human resource development based on competency. The purpose of this new system is

Corresponding Author: Haslinda Abdullah, Faculty of Defence Studies and Management, National Defence University of Malaysia, Kem Sungai Besi, 57000 Kuala Lumpur, Malaysia 
to motivate self improvement through continuous learning, increase knowledge-based workers and making them experts and being creative and innovative in carrying out daily work.

In this new system, further improvements were made to the performance appraisal system and the excellence awards. Improvements were also made in the area of opportunities for promotion, changes in salary structure and allowances with the hope that this would give rise to a generation of new public service that are capable in remaining competitive in this new era while fulfilling the expectations of the public whom they serve. Generally, the performance appraisal system allows an organization to measure and evaluate an individual employee's behavior and accomplishments over a specific period of time (Wiese and Buckley, 1998). However in the Malaysian civil service, performance appraisal is a continuous process of evaluating employees' performance throughout the year. Indeed in the Public Service Department of Malaysia, employees are looked at as assets or human capital to an organization and it is important to manage and motivate this asset. As an organization having motivated employees and high performing human capital can determine the success of an organization. In a well-managed organization, performance appraisal is the single most important management tool. It is the only management process that seems to have much influence over the employee's work and career. Some organizations claim that it is the most powerful instrument that they have to use in getting the energy of every employee towards achieving the company's mission, vision, value and strategic goals is through performance appraisal. Others have found them as a personnel department device for telling a worker how they are doing and to justify employees' salary increment.

However, the core of performance appraisal is to evaluate and measure employees' accomplishments over a period of time (Wiese and Buckley, 1998). Coutts and Schneider (2004) had said that it is a mechanism to evaluate the extent of employees' day to day performance which is linked to the goals established by the organization. Performance appraisal has been used at a varying degree of success in many organizations.

There have been several researches done in the field of performance appraisal internationally and nationally focusing in the public sector. Internationally, Koonmee (2009) conducted a study on the effects of the new performance system implemented in Thailand's public sector for the period of 2004-2007. In the USA, Lewis et al. (2009) examined the perception of intrinsically motivated employees on the effectiveness of performance appraisal. This research was carried out by analyzing data from 23 federal agencies by means of Merit Principal Survey conducted every 3 years. Similarly, in the United Kingdom, Cook and Crossman (2004) examined the satisfaction level of internal post personnel on its performance appraisal systems.

Studies on teachers' satisfaction on schools' performance appraisal systems were carried out by Kelly et al. (2008) in Singapore and by Irvine (2003) in New Zealand. On a different angle, studies on the perception and understanding of the performance appraisal process were conducted by Kavanagh et al. (2007) in an Australian scientific research centre and by Analoui and Fell (2002) in a university in the United Kingdom. Reinke had also studied the attitudes of county government employees toward their performance appraisal system in Georgia, USA. In Malaysia, the few studies available are by Dev Kumar (2005) who examined the importance of rater training in performing appraisals amongst the Malaysian Police Force and a study by Ahmad and Ali who focused on raters' understanding and cognitive processing on the decision making process in the public sector.

Indeed, performance appraisal is said to be the key to effective human resources management. In their influential discussion of performance appraisal, Latham and Wexley (1994) identified employee selection, appraisal, training and motivation as the four key systems necessary for insuring the proper management of an organization's human resources. Of these four human resource systems, they argued, performance appraisal as the most important because it is the prerequisite for establishing the other three systems (Roberts, 1995). This suggests the importance that should be given to performance appraisal in any organization. The general objective of this study is to obtain diplomatic officers' perceptions of the performance appraisal system. More specifically, this study aims to examine diplomatic officers' understanding and satisfaction of the appraisal system. This study also aims to identify if raters' characteristics influences their perceptions. The following research questions have been designed to achieve these objectives:

- How do diplomatic officers perceive the present performance appraisal system?

- What are the factors that influence their perceptions?

- What is their current understanding and satisfaction on the current performance appraisal system?

- What are the factors that contribute to raters' biasness in the performance appraisal system?

- What are their comments of the current performance appraisal system?

- What are their views on how the system should be? 
Performance management: According to Irvine (2003), performance management is a micro-descriptor that encompasses all the micro processes associated with personnel management, covering functions from the intake right to the exit of each staff. This therefore would include recruitment, retention, selection, appointment, employment contracts, registration, appraisal and assessment, professional and career development, succession planning, remuneration, discipline and dismissal. Performance management when implemented well can lead to important benefits for organizations (Aguinis et al., 2008).

For example, organizations with formal and systematic performance management systems are more likely to outperform others regarding financial outcomes and more likely to outperform others regarding additional outcomes including customer satisfaction, employee retention and other important metrics (Cascio, 2006). Indeed, it has been cited that performance appraisal is one of the contributing micro processes in performance management and it is central to the effectiveness of performance management (Irvine, 2003).

According to Abdullah et al. (2007), there are three critical strategies to assist organisations in improving performance. The first strategy is by creating management development initiatives. Here managers need to be provided with coaching, training and development on measuring and identifying performance standards and later communicating it to the employees. The monitoring of performance appraisal needs to be carried out from time to time. Secondly is by developing self direct and self esteemed employees. Employees' self esteem and self direction will emerge from the coaching process which will benefit both employees and managers. Lastly, the third strategy is by having reward strategies for employees whom had achieved performance standards.

Appraisal understanding: When a person understands the performance appraisal process, they would more likely be able to accept it (Roberts, 2003). Irvine (2003) had also said that clarity of guidelines and policy of implementing performance appraisal is vital if the organization wants to ensure understanding among its employees the need for implementation of the performance appraisal system. To develop a positive attitude, an employee needs to understand the purpose of the appraisal in the first place, the rating methods, the standards attached to it and the appraisal outcomes. It was suggested that employees have limited knowledge and understanding regarding their organization's appraisal policies and procedures (Analoui and Fell, 2002). Is this also true of the civil servants in the Malaysian Public Service? Is the policy regarding appraisal well disseminated? The policy, Secular No. 4, 2002 regarding the performance appraisal is available online to all diplomatic officers. It is however doubtful that employees read the secular or are even aware of its existence.

Appraisal satisfaction: It was suggested that employees are only satisfied with their performance appraisal if the performance appraisal process fulfils the criteria of fairness or distributive justice in it (Greenberg, 1986; Cook and Crossman, 2004). Greenberg (1986) also proposed that the key determinants of perceived justice are procedural justice and distributive justice. In procedural justice, employees perceive fairness from the evaluation process itself. The procedural justice suggests that employees' inputs are required before the evaluation process; there is a two way communication during the appraisal interview; employees must be given the opportunity for rebuttal; raters should be familiar with the employees work are the performance appraisal standards administered consistent at all times. In distributive justice, fairness is perceived from the outcomes by comparing the ratings that they had received for the work they have contributed. Two distributive factors that would affect employees' perception of performance evaluation as fair are: the performance evaluation is based on performance achieved, salary and promotion are based on the evaluation.

Both procedural justice and distributive justice is said to contribute equally to perception of fairness in performance appraisal systems (Greenberg, 1986). Indeed, Kelly et al. (2008) have suggested that the fairness of the appraisal system and the clarity of appraisal criteria are important for increasing the satisfaction of employees. In addition, Kavanagh et al. (2007) corroborated that the more control employees have on the performance appraisal process, the more they will consider the process to be fair. Therefore, performance appraisal has to be operated fairly and consistently by those responsible for carrying out appraisals. Fair performance appraisal systems coupled with effective training and involvement of employees with superiors ensures satisfaction that will contribute to increased organizational effectiveness (Cook and Crossman, 2004).

However, Kerssens-van Drongelen and Fisscher (2003) argued that appraisal satisfaction is based on seven factors, namely; content of appraisal forms, ratings of appraisal forms, company policy regarding appraisal, the appraisal procedures and physical characteristics of the appraisal forms and the appraisal process that has to be communicated to the employees so as there is general appraisal satisfaction among them. On the other end, 
Reinke contended that trust and acceptance of the performance appraisal process is just one incident in the ongoing relationship between supervisor and employee. Whatever occurs in the appraisal process is conditioned by the interpersonal relationship between the two parties. It is believed that the key to the relationship is trust. When there is trust, there is satisfaction.

A performance appraisal would result in personnel dissatisfaction and an impediment to systematic strategy implementation if there is no consistent alignment between performance appraisal as a human resource function and the strategic management of the organization as a whole (Caruth and Humphreys, 2008). Indeed, it has been reported by Kavanagh et al. (2007), in a research done on the Australian public sector employees that performance appraisal fairness practices would result in higher acceptance of decision of the appraisal, thereby resulting in a more positive organizational attitude including job satisfaction and organizational commitment as a whole. Fairness here would mean a belief in neutrality of the supervisor and the knowledge of the appraisal system.

Rater's characteristics: To successfully achieve the broad objectives of performance appraisal, the rating process must be technically sound with clear rating procedures (Dev Kumar, 2005). The rater must possess skills and motivation to conduct effective performance appraisals (Fink and Longenecker, 1998). Unfortunately, there are many who do not possess the skills required of a rater. Subjectivity and stereotype views of the raters may lead to discrimination in the appraisal process. Memory decay introduces bias into the rating process. Kozlowski et al. (1986) suggested that memory decay affected the ability to recall job and ratee information and resulted in halo error and subsequently inaccurate ratings. However, Dev Kumar (2005) contended that in reality, rater's memories are quite fallible and raters are bound by their own sets of likes, dislikes and expectations of people which may or may not be valid. This biasness in ratings manifests themselves in several ways. Dev Kumar (2005) suggested that rating biases can be grouped into five main categories. Firstly, leniency effect which is giving the undeserved employee higher rating than actual performance to avoid controversy over the appraisal is leniency effect. This would cause resentment among the better performers as poor performers are getting higher ratings. Secondly, the halo effect which occurs when rating is based on overall impression of the employee. The rater fails to differentiate the employee's weak points and strong points. The rater focuses on one factor as having paramount importance and gives employee a good or bad rating based on this one factor. Thirdly, central tendency effect is when the rater, not wanting to rock the boat, gives all employees an average rating, neither high nor low. This would bring about the failure of identifying the true range of differences between the employees. Fourthly, is the personal biasness effect. This is where consciously or unconsciously the rater may rate the employees lower or higher on the basis of race, origin, gender, age or other factors. Fifthly is the recency effect where most of the time the rater is not able to remember all that the employee had done, so he may base the appraisal on the most recent memory of the employee. If the employee had performed badly then he would get low marks and if he had performed well, he would get high marks.

According to Bretz et al. (1992) to eliminate any problems of bias, discrimination, favouritism or the like, a performance appraisal system needs to include a review mechanism. Allan (1994) had stated that the purpose of this managerial review is not to have the higher level manager perform a second appraisal; rather, it is for the purpose of auditing the evaluation for fairness, consistency, accuracy and assuring that the evaluator has carried out his or her function objectively. A secondary review also increases the amount of time devoted to the performance appraisal process. This will protect both the employee and the organization by making an effort to assure fairness and consistency in all employee evaluations. This fairness and consistency will rule out any biasness that may happen in the course of performing an appraisal.

\section{MATERIALS AND METHODS}

Research design: Quantitative research method was applied in this study to gain diplomatic officers' perceptions and understanding on performance appraisal. A survey design is employed because it is quick, economical and an accurate way of assessing information from a large group of diplomatic officers involved in this study.

Population and sampling: The target population of this study is diplomatic officers currently serving in the public office. The sampling method that was used is convenience sampling technique. This method adopted as it is a convenient, quick and economic way of gathering information from diplomatic officers' in various parts of the public service. There are 7,604 diplomatic officers as of September, 2009 from the top ranking to the lowest rank. The population of the study will be concentrated on the diplomatic officers of the middle level of grade M54-41 
as they are the ones mainly affected in the performance appraisal exercise. This is also where the difference in salary actually matters between each grade. The unit of analysis is the individual employees. The target population of the research is determined by using Krejcie and Morgan (1970)'s table for determining sample size from a given population. As there are 7,091 diplomatic officers as of September, 2009 from the levels of M54-41 that will be researched, the sample size selected is 364 diplomatic officers.

Research instrument: Characteristics of effective performance appraisal system were adapted and developed from an instrument by Longenecker and Goff (1992). In this study, a 4-point Likert Rating Scale was used from 1 (strongly disagree), 2 (disagree), 3 (agree) and 4 (strongly agree) to avoid neutral responses from respondents and to minimize lack of interest and uncertainty in the questionnaire. For questions regarding employees' level of understanding on the performance appraisal system and participation was adapted from Hartle (1997)'s series of questions on evaluation of performance appraisal system. The questionnaires were self administered to collect primary data.

A pilot test was held with the purpose of improving the questionnaire. A number of 15 respondents were targeted to ensure that the questionnaire was easy to understand and appropriate to capture the response of the target group. It was then discovered that some questions needed rephrasing to improve on respondents understanding and some questions had to be added to further capture the diplomatic officers perception on performance appraisal.

Data collection and response rate: For the purpose of this research, two sources of data were used. First, secondary data such as the official seculars were referred to and literature reviews from previous studies were looked at to obtain information on the subject matter of the research. These related journals and articles are obtained from trusted official website for referencing purpose. Secondly, primary data is crucial to obtained perceptions of the diplomatic officers on the performance appraisal and is obtained through a questionnaire survey. The questionnaires were distributed via e-mail and by hand to 370 respondents. Avenues were made available by the researcher to the respondents to clarify any misunderstandings in the questionnaire. The questionnaires were to be completed within the 2 weeks time period given. However due to it being a year-end holiday period, the time given was further extended for another 2 weeks and the questionnaires were returned to the researchers in due course. After the 1st week, reminders were sent out through emails and phone calls made to the respondents. Second reminders were sent out as the response rate was low. Out of 370 questionnaires sent out, only 106 were returned representing $28.6 \%$.

Data analysis: Data received were analyzed using the Statistical Package for Social Sciences (SPSS) to obtain the results from the questionnaire. All questionnaires received were screened for errors which can distort data and consequently causing the analysis to be incorrect. All 106 responses received were valid data with no errors. Descriptive analysis was used to search for frequency distributions, mean and standard deviations. In addition, there were two open ended questions in the questionnaire. The responses from these were grouped according to the relevant themes and analyzed.

\section{RESULTS AND DISCUSSION}

Purpose of the performance appraisal: As shown in Table 1, the results showed that a majority of the diplomatic officers agreed that the purpose of appraisal is generally for promotions $(85.8 \%)$ and it is done mainly to comply to the current policy in the organization $(78.3 \%)$. In addition, this study found that the purpose of performance appraisal in the public service department is for yearly salary adjustments and for training needs assessment. Performing performance appraisals for the purpose of employee layoffs and dismissals was disagreed by $66.8 \%$ of the diplomatic officers. Indeed these findings have been corroborated by Irvine (2003), Roberts, (1995) and Latham and Wexley (1994) who contended that the purpose of performance appraisals is to support the main functions of human resources management as found in this study.

Most reliable and effective source of performance feedback: According to the current appraisal system, superiors are the source of reliable and effective feedback for the appraisees as seen in Table 2. Although, $61.3 \%$ of the diplomatic officers agreed that their superiors should be the ones to grade them, grading by peers came close at

Table 1: Purpose of appraisal

\begin{tabular}{lcccc}
\hline & Percentage & & & \\
& -1 & & \\
& $\begin{array}{l}\text { Strongly } \\
\text { disagree }\end{array}$ & Disagree & Agree & $\begin{array}{c}\text { Strongly } \\
\text { agree }\end{array}$ \\
Purposes & 1.9 & 12.3 & 61.3 & 24.5 \\
Promotion & 4.7 & 25.5 & 56.6 & 13.2 \\
Career planning & 6.6 & 20.8 & 48.1 & 24.5 \\
Training and development & 6.6 & 19.8 & 53.8 & 19.8 \\
Salary decision & 25.5 & 44.3 & 21.7 & 8.5 \\
Layoff/dismissal & 6.6 & 15.1 & 43.4 & 34.9 \\
According to current policy & 6.6 & & &
\end{tabular}


Int. Business Manage., 6 (2): 213-222, 2012

\begin{tabular}{|c|c|c|c|c|}
\hline \multirow[b]{2}{*}{ Reliable source of feedback } & \multicolumn{4}{|c|}{ Percentage } \\
\hline & $\begin{array}{l}\text { Strongly } \\
\text { disagree }\end{array}$ & Disagree & Agree & $\begin{array}{c}\text { Strongly } \\
\text { agree }\end{array}$ \\
\hline My immediate superior & - & 10.4 & 28.3 & 61.3 \\
\hline My peers & 2.8 & 8.5 & 58.5 & 30.2 \\
\hline My subordinates & 3.8 & 17.9 & 44.3 & 34.0 \\
\hline Myself & 7.5 & 17.0 & 49.1 & 26.4 \\
\hline Top management & 5.7 & 24.5 & 38.7 & 31.1 \\
\hline Human resource personnel & 16.0 & 40.6 & 34.0 & 9.4 \\
\hline The customers & 7.5 & 17.0 & 41.5 & 34.0 \\
\hline
\end{tabular}

Table 3: Appraisal frequency

\begin{tabular}{|c|c|c|c|c|}
\hline \multirow[b]{2}{*}{ Appraisal frequency } & \multicolumn{4}{|c|}{ Percentage } \\
\hline & $\begin{array}{l}\text { Strongly } \\
\text { disagree }\end{array}$ & Disagree & Agree & $\begin{array}{c}\text { Strongly } \\
\text { agree }\end{array}$ \\
\hline Annually & 1.9 & 7.5 & 32.1 & 58.5 \\
\hline Semi-annually & 30.2 & 29.2 & 27.4 & 13.2 \\
\hline Quarterly & 33.0 & 35.8 & 22.6 & 8.5 \\
\hline Before promotion & 17.0 & 17.9 & 35.8 & 29.2 \\
\hline Before demotion/termination & 34.9 & 33.0 & 21.7 & 10.4 \\
\hline Never & 60.4 & 23.6 & 6.6 & 9.4 \\
\hline
\end{tabular}

$58.5 \%$. This may be an indication of the readiness of the diplomatic officers to accept the $360^{\circ}$ feedback method of evaluation.

Appraisal frequency: The frequency in which performance appraisal is measured can be shown in the Table 3. According to the Government Service Secular, the performance appraisal has to be conducted once at the end of the year with a review carried out in the middle of the year. However from the survey, the results indicated there are no agencies adhered to the secular as they should. It is indicated that most agencies performed performance appraisal once a year $(90.6 \%)$ which is normally at the end of the year whereas, $65 \%$ reported that it is conducted just before it is time for promotions.

Rating method used by superior: In this study it can be seen that there are no specific methods used for performance appraisal. The findings indicated that a superior uses all 5 factors when it comes to rating their employees. As shown in Table 4, the rating method used by superior in rating the diplomatic officers are by attributing poor or good performance based on specific behaviours of the officer $(78.3 \%)$, record of ratings on numerical scale based on specific aspects of officers' performance $(75.5 \%)$ and that rating is also based on critical incidence day-to-day work behavior $(74.6 \%)$.

Understanding and satisfaction: The results of the analysis indicated that most of the respondents are satisfied on the clarity of the performance appraisals and goals. For example, at the beginning of the year, work description and related goals in most government

\begin{tabular}{lcccc} 
Table 4: Rating methods & & & & \\
\hline & Percentage & & & \\
& $\begin{array}{l}\text { Strongly } \\
\text { disagree }\end{array}$ & Disagree & Agree & $\begin{array}{c}\text { Strongly } \\
\text { agree }\end{array}$ \\
$\begin{array}{l}\text { Rating method } \\
\text { used by superior }\end{array}$ & 4.7 & 20.8 & 55.7 & 18.9 \\
\hline $\begin{array}{l}\text { Rating based on record } \\
\text { of day to day work behavior }\end{array}$ & & & & \\
$\begin{array}{l}\text { (Critical incidence) } \\
\begin{array}{l}\text { Ranks employees' from } \\
\text { best to worst (Ranking Method) }\end{array}\end{array}$ & 12.3 & 33.0 & 44.3 & 10.4 \\
$\begin{array}{l}\text { Records rating on numerical } \\
\text { scale based on specific aspects } \\
\text { of ratees' performance }\end{array}$ & 5.7 & 18.9 & 42.5 & 33.0 \\
$\begin{array}{l}\text { By attributing poor or good } \\
\text { performance based on specific } \\
\text { behaviours of the rate (BOS) }\end{array}$ & 5.7 & 16.0 & 54.7 & 23.6 \\
$\begin{array}{l}\text { Allowing each ratee to have their } \\
\text { turn in ranking the highest }\end{array}$ & 14.2 & 42.5 & 32.1 & 11.3 \\
\hline
\end{tabular}

agencies are clearly outlined and set as agreed by $82.1 \%$ of the respondents and $70.7 \%$ indicated that they are involved in setting this performance standards and work goals. Annual work targets in most agencies are also set early in the year says $84.9 \%$ of the respondents. In addition, most of the respondents agreed that the performance standards are specific $(90.6 \%)$, measurable $(85.9 \%)$, achievable $(87.8 \%)$, relevant $(91.5 \%)$ and timebound (84\%).

Despite the lack of understanding on the appraisal form, indicated by $72.7 \%$ responses, the rating method used on the form was appropriate (92.5\%) and superior also uses the rating method specified in the forms $(84.9 \%)$. Hence, the forms require reviewing and further improved for further understanding and this finding is agreed by 92.5 of the respondents who suggest that the performance appraisal forms and system needs improvement.

In relation to ethics and ethical conduct during the appraisal process, it is agreed by $84.9 \%$ of the respondents that superiors are quite honest and ethical during the entire appraisal process and criticisms made during the appraisal meeting are based on facts, not on opinions $(95.8 \%)$. This is agreed by $91.5 \%$ of the respondents who contended that both raters and rates should be ethical in the entire performance measurement process. In relation to diplomatic officers' believe in the current performance appraisal system, it is found that almost half of the respondents do not believe in the current appraisal system set for them. This is seen in the responses of $49.1 \%$ agreed that they are indifferent and $50.9 \%$ disagreed. Hence, this questioned the purpose of carrying out performance appraisal if the diplomatic officers themselves do not believe in the system.

Mid-term discussions and review according to the Government Service Secular is a requisite but only $59.4 \%$ agreed that it was carried out as compared to $40.6 \%$ who reported that mid-term reviews was not carried out in their respective departments. Mid-term reviews allows changes 
to be made to the setting of performance standards, yearly work related goals and job description of the employee. Secrecy of the performance appraisal is quite high in the public service in general. An employee should be allowed to know the rating received for the year. However, only $54.7 \%$ of the respondents are satisfied and agreed that they know the results or rating of the appraisals performed whilst the remaining do not get to know the outcome of the appraisal results.

It is therefore vital for the growth of the organization that the superior calls in his/her employee and informs them of the reason why certain marks have been given. This is because goods marks would motivate the employee and poor marks only go to show that there is room for improvement and to better one self and in the long run for the good of the organization. It is critical that any weaknesses are known for further improvement. Generally in the opinion of $92.5 \%$ of the respondents, the performance appraisal needs to be improved and $84.9 \%$ agreed that it is still a necessary tool in the management of human capital of an organization. As to whether it should be abolished, $72.2 \%$ agreed that it should not be abolished. It still serves its purpose in the service as confirmed by $77.4 \%$ of the respondents. As to the issue of fairness, $67.9 \%$ of the respondents agreed that the current appraisal is fair. There is however, a substantial percentage $(32.1 \%)$ of the diplomatic officers who feels that the current performance appraisal is unfair. This finding suggests to a certain extent, practice of unfairness may have occurred.

Rater's characteristics and competency: The results of the analysis reveals that based on ten factors indicating areas in which biasness may occur, $82.1 \%$ of respondents agreed that favoritism tops the list.

Other factors such as rater's working experience $(66 \%$, mean $=2.76, \mathrm{SD}=0.94)$, gender $(58.5 \%$, mean $=2.6$, $\mathrm{SD}=0.97)$ race $(54.7 \%$, mean $=2.5, \mathrm{SD}=0.89)$, education level $(50.9 \%$, mean $=2.4, \mathrm{SD}=0.92)$ can contribute to biasness amongst raters.

In addition, it is indicated that ratee's personal attractiveness, social status and networking can also contribute to rater's biasness during the performance appraisal process. Indeed, this finding is supported by numerous comments from the respondents albeit rephrased differently. For example, as quoted as:

- Bosses should be frequently reminded that the appraisal is for the improvement of the employee and not for the detriment of the employee. Should be frank in their appraisal and should not be based on favoritism or biasness
- Superiors must possess objectivity of mind, fidelity of character, honesty in interpersonal relations, integrity in evaluating work, fairness and fairness in assessing subordinate

- Complaints from officers regarding unfair treatment should be taken seriously and looked into by management

- There is tendency for some of the superior to be bias in rating their subordinates giving them high marks

In tabulating the mistakes usually made by the superior, central tendencies and recency error has been agreed by the respondents as the highest at $69.8 \%$ followed closely by the halo error at $67 \%$ and personal biasness effect at $66.9 \%$. Central tendencies is where the superior gives the employee a mid range rating and not one that he deserves whereas recency is where the most recent performance of the employee whether good or bad will affect superior's judgment on the rating he/she should receive. Personal biasness may include behaviours such as attitudes or preferences on race, gender, religion or even class of people. On the other hand, contrary to popular belief, superior's leniency has been rated the lowest at $48.1 \%$. This still reflects a big percentage as it is almost $50 \%$ of the total respondents. In answering the question on subordinates who are close to their superior gets better performance ratings, $80.2 \%$ of the respondents agreed that this does occur in the Public Diplomatic Services. A total of $72.6 \%$ of the respondents also agreed that an employee's previous level of performance rating do affect the superiors evaluation of their current performance. Whether performance should count and not personalities, received almost equal percentage, i.e., $54.7 \%$ agreed that it should be performance that counts to $45.3 \%$ had said that personalities should also count in performance appraisal. In receiving negative feedback openly, $60.4 \%$ of respondents agreed to it. There is an issue of culture here which defies what it used to be. Asians tend to be a culture that do not like public admonishment nor appraisal. This is obviously changing. Groesschl (2003) has identified culture as an important factor influencing the understanding and interpretation of the appraisal process, its development, implementation and other appraisal related elements and functions. What may be appropriate in one culture may prove to be inappropriate for another culture. Culture may change and this should be noted. The question of employees holding different cultural values also received almost similar ratings. Of the total percentage, $55.7 \%$ agreed that their superiors are sensitive to their cultures while $44.3 \%$ disagreed that their superiors are sensitive to their cultures. This eventually affects the satisfaction of the 
appraisal performance and the rater's characteristics towards the employee. In the issue of training, $72.7 \%$ agreed that rater's should be sent for training or refresher courses to help them to rate their employees objectively and with minimal biasness.

\section{CONCLUSION}

The first finding is on the issue of elements of appraisal. From the findings, most of the respondents agreed that promotion is the main purpose performance appraisal is carried out and the most effective and reliable source of feedback would be from their immediate superiors. In this issue however, the respondents had also indicated that even their peers and subordinates are considered to be relevant source of feedback. This indicates the want for $360^{\circ}$ feedback. The researchers of The power of $360^{\circ}$ feedback, Rao and Rao (2005) had mentioned that the 360 feedback tool should be used more as a mental tool than an appraisal tool in Asian countries and the African region. Although, the $360^{\circ}$ feedback is a good appraisal tool, it may not work in relationship oriented countries. This system need to be implemented as a project to see the outcome and effects on the system. On the issue of appraisal method from the survey, it can be concluded that there are no particular method used. There is evidence of many types of methods being applied. Therefore, the elements do affect the view and perception of Public Diplomatic Service Officers on the appraisal, especially on the issue of reliable and effective source of feedback.

The second finding is on the issue of understanding and satisfaction of the appraisal system. The important elements are on the issues of Public Diplomatic Service Officers being indifferent to the rating that they received, the dissatisfaction that their appraisal results are kept from them and that mid term reviews are not carried out on almost half of the respondents. The respondents however have no difficulties in understanding the forms of the appraisal and the rating method. However, it can be seen form the research that understanding of the forms does not affect the perception of the Public Diplomatic Service Officers. The respondents believe that ethics is an important element in performance appraisal and that both rater and ratee should be ethical during the entire appraisal process. A large number of respondents agreed that raters should be sent for some training or refresher course annually to remind them on how to evaluate an employee.

According to Irvine (2003) and Dev Kumar (2005), long term training is needed to help appraisers to develop educative process interactions with appraisees. Lastly from the findings, it can be said that raters characteristics affect the view of performance appraisal the most. Based on the survey, favoritism and appraisal based on personalities rather than performance causes the most dissatisfaction, thus affecting the perception of the system.

A large number of respondents indicated that they are willing to accept negative feedback openly, instead of keeping it as a secret. The culture of Asians generally is to shy away from giving negative feedback to avoid insult of offending the other person. Performance may be interpreted or valued differently based on cultural values and belief systems. Trompenaars and Hampden-Turner (1997) seem to indicate that Malaysia is more a particularism country instead of universalism where relationships are more important than rules. Malaysians would generally use relationships to determine subordinates performance appraisal making it rarely objectively appraised. Therefore the appraisal score do not objectively reflect a person's performance in such a background.

The open ended questions had given a lot of insight as to the weaknesses of the current system faced by the employees. Some of the weaknesses are that the appraisal system is too subjective and that there is little discussion held between the rater and ratee. Due to the subjectivity, there is no clear standard in rating and this standard also differs from one organization to another. Favoritism is also rampant when awarding marks to employees. Suggestions were also made to improve the system from time to time according to changes in the surroundings of the public service such as training and to do review the system from time to time.

\section{IMPLICATIONS}

This study presents some implications for the appraisal process carried out for the Public Diplomatic Service Officers. The appraisal system is meant to motivate employees by having their performance annually reviewed. Those who do well are given monetary rewards. The research however shows that employee are not motivated by just extrinsic factors but rather by intrinsic factors such as job satisfaction, recognition for work done and being able to develop in the organization. The first implication is factors satisfying employees have changed; therefore the system should change with it.

The implication on the issue of rater's characteristics is that training is needed to improve the ways in which raters' rate their employees. Thus, improving the appraisal system and bringing it to a newer level of appraisal. Ratings would reflect the true nature of the job 
performance of the employee. The $360^{\circ}$ feedback as suggested by many of the respondents minimizes rater's characteristics error and allows for transparency in the system as contrast to the system right now which is shrouded with secrecy. This type of appraisal system involves everyone and would make everyone involved in the appraisal accountable for each other. The overall implication is that the current appraisal system needs to be improved, taking into account certain suggestions put forth above by the employees themselves.

\section{LIMITATIONS}

There are some limitations that would define the scope of the study. Firstly, the limitations were mainly due to time and financial constraints causing the study to only be carried out only on selected categories of Public Diplomatic Service Officers.

The sampling method used was one of convenience sampling, hence may result in some sample biasness. This method is chosen to assist in achieving the number of sample size required. There was a time in the study where the researcher could not obtain a good number of respondents due to the holiday season at the end of the year. The length of time to collect data had to be extended to get a good sample as it affects the credibility of this study. This however had not affected the validity of the data obtained.

\section{RECOMMENDATIONS}

For future study, it is recommended that a longitudinal study is undertaken which covers a wider group of Public Diplomatic Service Officers from all departments, to obtain a richer understanding of the perception of Public Diplomatic Service Officers on the appraisal system. It is also recommended that a collaborative study is carried out with PSD. This would involve the department concern directly with regards to the issue at hand and would widen the scope of the study.

For future studies, random sampling is used to cover all groups of Public Diplomatic Service Officers from all departments for a better scope of Public Diplomatic Service Officers. In analyzing the data, descriptive analysis was used. For future studies, it is recommended that a relationship study is carried out to further understand the effectiveness of the current performance appraisal system. For future research, this study be widened to involve a larger number of Public Diplomatic Service Officers from all sections of the public service as their perceptions may defer due to the place of work. For this research, only three scopes were used to acquire the perception of Public Diplomatic Service Officers. Other elements such as culture, background of work, different grades of Public Diplomatic Service Officers affect the perception of Public Diplomatic Service Officers.

On the whole, the respondents do understand the current appraisal system used but they are not satisfied with it. This had affected their perception of the system. There is a need for the system to be reanalyzed to achieve a better perception. Despite some limitations in the findings, the study was able to show that there is dissatisfaction and this has to be addressed by the public service. Job satisfaction will lead to better performance which benefits the organization.

\section{ACKNOWLEDGEMENTS}

Firstly, this study will facilitate in adding knowledge to the existing literature on perception of performance appraisal in the public service, especially in the Public Diplomatic Service. Based on data researched, there is very little literature on this particular topic. This research may assist future researchers who are interested in carrying out a study in this field or scope. Secondly, this research will also provide information to the Public Service Department about the Diplomatic officer's perception of the current appraisal system. Based on the response made this information may be used to further improve the current system. The policy regarding performance appraisal for Public Diplomatic Service Officers may be improved. Thirdly and finally, this study can contribute to the Public Diplomatic Service Officers as the general society affected by this system, in ensuring a fair and acceptable appraisal is carried out at all times if and when amendments are done to the current system.

\section{REFERENCES}

Abdullah, H., R. Che Rose, A. Salleh and N. Kumar, 2007. Measuring and managing performance improvement in the manufacturing sector. Eur. J. Soc. Sci., 5: 157-166.

Aguinis, H., M.C. Sturman and C.A. Pierce, 2008. Comparison of three meta-analytic procedures for estimating moderating effects of categorical variables. Organiz. Res. Methods, 11: 9-34.

Allan, P., 1994. Designing and implementing an effective performance appraisal system. Rev. Bus., 19: 2-6.

Analoui, F. and P. Fell, 2002. Have you been appraised? A survey of the university administrative staff. Int. J. Educ. Manage., 16: 279-287.

Bretz, Jr. R.D., G.T. Milkovich and Read, 1992. The current state of performance appraisal research and practice: Concerns, directions and implications. CAHRS Working Paper Series Cornell University ILR School Year 1992 
Caruth, D.L. and J.H. Humphreys, 2008. Performance appraisal: Essential characteristics for strategic control. Measur. Bus. Excell., 12: 24-32.

Cascio, W.F., 2006. Global Performance Management Systems. In: Handbook of Research in International Human Resources Management, Bjorkman, I.I. and G. Stahl (Eds.). Edward Elgar Publishing Ltd., Cheltenham, UK., pp: 176-196.

Cook, J. and A. Crossman, 2004. Satisfaction with performance appraisal system: A study of role perceptions. J. Manage. Psychol., 19: 526-541.

Coutts, L.M. and F.W. Schneider, 2004. Police officer performance appraisal systems: How good are they? Policing. Int. J. Police Strategies Manage., 27: 67-81.

Dev Kumar, D.S.P., 2005. Performance appraisal: The importance of rater training. J. Kuala Lumpur Royal Malaysia Police College, 4: 1-17.

Fink, L.S. and C.O. Longenecker, 1998. Training as a performance appraisal improvement strategy. Career Dev. Int., 3: 243-251.

Greenberg, J., 1986. Determinants of perceived fairness of performance evaluations. J. Applied Psychol., $71: 340-342$.

Groesschl, S., 2003. Cultural implications for the appraisal process. Cross Cultural Manage. Partington, 10: 67-79.

Hartle, F., 1997. Tranforming the Performance Management Process. 2nd Edn., Kogan Page Publication, UK., ISBN: 9780749424787, Pages: 245.

Irvine, E.P., 2003. Key features of appraisal effectiveness. Int. J. Educ. Manage., 17: 170-178.

Kavanagh, P., J. Benson and M. Brown, 2007. Understanding performance appraisal fairness. Asia Pacific J. Hum. Res., 45: 132-150.

Kelly, K.O., S.Y.A. Ang, W.L. Chong and W.S. Hu, 2008. Teacher appraisal and its outcomes in Singapore primary schools. J. Educ. Admin., 46: 39-54.

Kerssens-van Drongelen, I.C. and O.A.M. Fisscher, 2003. Ethical dilemmas in performance. Measur. J. Bus. Ethics, 45: 51-63.
Koonmee, K., 2009. Effects of Performance management and incentive allocation on development of thai public services and officers. Bus. Rev. Cambridge, 12: 163-169.

Kozlowski, S.W.J., M.P. Kirsch and G.T. Chao, 1986. Job knowledge, ratee familiarity, conceptual similarity and halo error: An exploration. J. Applied Psychol., 71: 45-49.

Krejcie, R.V. and D.W. Morgan, 1970. Determining sample size for research activities. Edu. Psychol. Measur., 30: $607-610$.

Latham, G.P. and K.N. Wexley, 1994. Increasing productivity through performance appraisal. 2nd Edn., Addison-Wesley, Boston, MA USA.

Lewis, C., M. Koyasu, S. Oh, A. Ogawa, B. Short and Z. Huang, 2009. Culture, executive function and social understanding. New Direc. Child Adolescent Dev., 123: 69-85.

Longenecker and Goff, 1992. Performance appraisal effectiveness: A matter of perspective. SAM-Adv. Manage. J., Appl. Psychol., 71: 45-49.

Rao, T.V. and R. Rao, 2005. The Power of 360 Degree Feedback: Maximising Managerial and Leadership Effectiveness. Sage Publications, New Delhi, India.

Roberts, G.E., 1995. Developmental performance appraisal in municipal government: An antidote for deadly disease?. Rev. Public Personnel Admin., 15: 17-43.

Roberts, G.E., 2003. Employee performance appraisal system participation: A technique that works. Public Personnel Manage., 32: 89-98.

Trompenaars, F. and C. Hampden-Turner, 1997. Reading the Waves of Culture. 2nd Edn., Nicholas Brealey, London.

Wiese, D.S. and M.R. Buckley, 1998. The evolution of the performance appraisal process. J. Manage. History, 4: 233-249. 